\title{
NÚMERO DE FRUTOS POR PLANTA NA PRODUÇÃO E QUALIDADE DE HÍBRIDOS DE MELÃO RENDILHADO CULTIVADO EM SUBSTRATO
}

Sueyde Fernandes de Oliveira ${ }^{1}$; Renata Castoldi²; Hamilton Cesar de Oliveira Charlo ${ }^{3}$; Pablo Furlan Vargas ${ }^{4}$; Leila Trevisan Braz ${ }^{2}$

${ }^{1}$ USP-ESALQ, Departamento de Produção Vegetal - Setor de Agricultura, e-mail: sueydefo@ yahoo.com.br

${ }^{2}$ UNESP-FCAV, Departamento de Produção Vegetal, e-mail: rcastoldi@gmail.com

${ }^{3}$ Instituto Federal de Educação Ciência e Tecnologia do Triângulo Mineiro (IFTM), e-mail: hamiltoncharlo@gmail.com

${ }^{4}$ UNESP/Unidade Diferenciada de Registro, e-mail: pfvargas@ gmail.com

\section{RESUMO}

O presente trabalho teve por objetivo avaliar dois híbridos de melão rendilhado e o efeito do número de frutos por planta na produção e qualidade de melão rendilhado cultivado em fibra da casca de coco com fertirrigação. Com base nos resultados obtidos, levando-se em consideração as características quantitativas e qualitativas dos frutos, conclui-se que três frutos por planta proporciona maior produção com melhores características qualitativas, e o híbrido Bônus $\mathrm{n}^{\circ} 2$ produz frutos de melhor qualidade.

Palavras-chave: Cucumis melo (L.) var. reticulatus, condução, fibra de coco

\section{NUMBER OF FRUIT PER PLANT IN THE PRODUCTION AND QUALITY OF NET MELON CULTIVATED IN SUBSTRATE}

\section{ABSTRACT}

This study aimed at evaluate two hybrid of net melon and the effect of number of fruits per plant in the production and quality of net melon grown in coconut fiber and fertirrigation. Based on the results, taking into account the quantitative and qualitative characteristics of fruits, one conclude that three fruits per plant provide higher production with better qualitative characteristics, and the hybrid Bônus $\mathrm{n}^{\circ} 2$ produces fruits with better quality.

Keywords: Cucumis melo (L.) var. reticulatus, conduction, coconut fiber

\section{INTRODUÇÃO}

O meloeiro (Cucumis melo L.) é uma planta da família das cucurbitáceas, sendo uma espécie subdividida em grupos botânicos, dos quais os mais conhecidos são Inodorus, Reticulatus e Cantalupensis. Estes dois últimos são considerados melões nobres, por possuírem frutos de melhor qualidade, com aroma e sabor característicos, e de melhor apresentação (PÁDUA, 2001).

Conhecido na região Nordeste como melão japonês ou cantaloupe, o melão rendilhado caracteriza-se por apresentar plantas de porte rasteiro, caule herbáceo muito ramificado e que produz frutos com casca rendilhada (COELHO et al., 2003). Além disso, apresentam formato redondo a ovalado, peso variando de 1 a $3 \mathrm{~kg}$, aroma característico e polpa bastante doce.

Com a consolidação da produção de hortaliças em estufa, o cultivo do melão rendilhado recebeu maior atenção dos produtores, especialmente nos estados de São Paulo e Paraná (PURQUERIO et al., 2003). O cultivo em casa-de-vegetação, comparado às condições de campo, apresenta vantagens como maiores rendimentos e qualidade dos produtos. No entanto, a realização de vários ciclos consecutivos pode levar à salinização do 
solo, tornando promissora a prática do plantio em substrato com fertirrigação.

Embora o sistema hidropônico tenha crescido em importância econômica e comercial, são necessários mais estudos para obtenção de melhores resultados no cultivo de determinada espécie vegetal, aumentar o rendimento e qualidade dos frutos, definir as melhores cultivares, o melhor sistema de cultivo e tipo de estrutura da casa de vegetação, aliada às condições climáticas de cada região (SANDRI et al., 2007).

Com a perspectiva de novos nichos de mercado, frente à ampla disponibilidade de materiais, é necessário avaliar os cultivares mais adaptados para cada região produtora e o sistema de cultivo. Através de interações estabelecidas entre as plantas, o ambiente e as práticas fitotécnicas utilizadas, é possível obter diferentes respostas fisiológicas e, consequentemente, agronômicas, não só do ponto de vista quantitativo (rendimento), como também qualitativo (características sensoriais e nutricionais).

Essas associações são bastante evidenciadas no meloeiro, sendo que sua eficiência é maior em condições ambientais adequadas, favorecidas por práticas de manejo como densidade de cultivo, cobertura do solo, métodos de condução de plantas, podas e raleio (MARTINS et al., 1998).

O sistema de cultivo adotado interfere nos processos metabólicos e de transporte que governam o fluxo de assimilados e, consequentemente, a distribuição de matéria seca nos órgãos de uma planta. Esses assimilados podem ser utilizados como fonte energética necessária para o funcionamento da planta, e serem transportados e armazenados temporariamente em órgãos de reserva ou nos drenos (DUARTE et al., 2008), como nos frutos do meloeiro.

$\mathrm{O}$ equilíbrio entre as frações vegetativa e reprodutiva pode ser manipulado aumentando ou diminuindo a força de fonte (taxa fotossintética da cultura) ou a força de dreno (demanda por assimilados). Com isso, o balanço apropriado entre o aporte e a demanda de assimilados pela planta tem grande importância para maximizar a produção, e pode ser obtido através da adequada relação fonte:dreno (DUARTE et al., 2008). Uma prática da cultura que pode ser usada para alterar a relação fonte-dreno é manipular o número de frutos por planta, de acordo com a exigência do mercado.

Para o produtor, o mais interessante é que a máxima proporção de assimilados seja destinada aos frutos. Porém, existem limites para a relação generativo:vegetativo, já que as plantas necessitam destinar uma quantidade suficiente para os demais órgãos, a fim de captar luz solar e acumular água e nutrientes para manter a sua capacidade produtiva (VALANTIN et al., 1999; PEIL \& GÁLVEZ, 2005).

O número de frutos estabelecido como ideal varia de acordo com a cultivar, a época de cultivo, o manejo nutricional, dentre outros, pois afetam a morfologia da planta e a competição por assimilados, aumentando ou diminuindo a fixação e crescimento de frutos. Portanto, vários são os trabalhos realizados com o objetivo de avaliar diferentes manejos para o meloeiro, a fim de obter melhorias na produção e qualidade dos frutos.

Diante do exposto, o presente trabalho teve por objetivo avaliar dois híbridos de melão rendilhado e o efeito do número de frutos por planta na produção e qualidade dos frutos cultivados em fibra da casca de coco com fertirrigação.

\section{MATERIAL E MÉTODOS}

$\mathrm{O}$ experimento foi conduzido em casa de vegetação, no Setor de Olericultura e Plantas Aromático-Medicinais do Departamento de Produção Vegetal, da 
Faculdade de Ciências Agrárias e Veterinárias - UNESP - Campus de Jaboticabal-SP, cujas coordenadas geográficas são $21^{\circ} 14^{\prime} 05^{\prime}$ " latitude sul, $48^{\circ}$ 17 ' 09 " longitude oeste e altitude de $614 \mathrm{~m}$.

O delineamento experimental utilizado foi de blocos ao acaso, em esquema fatorial $3 \times 2$, sendo os fatores avaliados número de frutos por planta (dois, três e quatro) e dois híbridos de melão rendilhado (Bônus $\mathrm{n}^{\mathrm{o}} 2$ e Louis), com quatro repetições. Cada parcela constou de sete plantas, sendo avaliadas as cinco plantas centrais de cada parcela.

A semeadura foi realizada em 23-012007, em bandejas de poliestireno expandido com capacidade para 128 células, preenchidas com substratos Plantmax HT®, colocando-se uma semente por célula. As bandejas foram acondicionadas em ambiente protegido do tipo arco, com dimensões de 15 $\mathrm{m}$ de comprimento, $7 \mathrm{~m}$ de largura, $3 \mathrm{~m}$ de pé-direito e com cobertura de polietileno de baixa densidade (PEBD) de 150 micra de espessura, sendo a irrigação realizada duas vezes ao dia.

O transplante para a casa de vegetação foi realizado aos 15 dias após a semeadura, quando as mudas apresentavam a primeira folha definitiva completamente desenvolvida. $\mathrm{O}$ cultivo do melão foi realizado em vasos, com capacidade total de $13 \mathrm{dm}^{3}$ preenchidos com fibra da casca de coco Golden $\mathrm{Mix}^{\circledR}$ Misto 98, com as características físicas: porosidade total de $94 \%$, capacidade de aeração de $35 \%$, capacidade de retenção de água disponível 41\% (Amafibra, s.d.), e químicas: $\mathrm{pH}$ 5,1; condutividade elétrica $1,0 \mathrm{dSm}^{-1}$; N-nitrato $8,1 \mathrm{mgL}^{-1}$; fósforo $53,0 \mathrm{mgL}^{-1}$; cloreto 44,6 $\mathrm{mgL}^{-1}$; enxofre $92,1 \mathrm{mgL}^{-1}$; N-amônia 17,7 $\mathrm{mgL}^{-1}$; potássio $270,1 \mathrm{mgL}^{-1}$; sódio 12,6 $\mathrm{mgL}^{-1}$; cálcio 9,9 $\mathrm{mgL}^{-1}$; magnésio $6,6 \mathrm{mgL}^{-}$ ${ }^{1}$; boro $0,5^{-1}$; cobre $0,1 \mathrm{mgL}^{-1}$; ferro 0,4 $\mathrm{mgL}^{-1}$; manganês $0,1 \mathrm{mgL}^{-1}$; e, zinco 0,5 $\mathrm{mgL}^{-1}$. Os vasos foram dispostos em fileiras duplas nos espaçamentos $0,5 \mathrm{~m} \mathrm{x} 0,8 \mathrm{~m}$ entre fileiras simples e $1,10 \mathrm{~m}$ entre fileiras duplas, na densidade de 21 plantas por ha.

Foi utilizada irrigação por gotejamento com solução nutritiva recomendada por Castellane \& Araújo (1994), sendo a recomendação, em mgL ${ }^{-1}$, de: 200 de N; 40 de P; 165 de K; 150 de Ca; 133 de $\mathrm{Mg} ; 100$ de S; 0,3 de B; 2,2 de Fe; 0,6 de Mn; 0,3 de Zn; 0,05 de $\mathrm{Cu}$ e 0,05 de Mo. A fertirrigação foi controlada por um temporizador, tendo início às $7 \mathrm{~h}$ e término às $18 \mathrm{~h}$, através de gotejadores com vazão de $14 \mathrm{mLmin}^{-1}$. Quando as plantas estavam na fase inicial, foram realizados pulsos de 10 minutos a cada hora, e com o desenvolvimento da cultura o período foi aumentado, chegando ao final do ciclo com 15 minutos a cada hora.

O tutoramento das plantas foi feito com fitilhos plásticos presos a arames localizados rente ao vaso e a $2,0 \mathrm{~m}$ de altura. Quando a planta atingiu máxima altura foi realizada capação, sendo conduzida uma planta por vaso e uma haste por planta. A partir do $8^{\circ}$ nó caulinar foi permitido o desenvolvimento dos brotos (hastes secundárias) para a fixação dos frutos. A polinização foi realizada manualmente e os frutos foram fixados entre o $10^{\circ}$ e $18^{\circ}$ internódios, e sempre que necessário foi efetuado o raleio, para deixar dois, três ou quatro frutos, de acordo com o tratamento estabelecido. Foi realizada a poda apical dos brotos laterais deixando-se uma folha depois do fruto. Para a sustentação dos frutos foram utilizados ganchos feitos com arame encapado e presos através de fios de ráfia aos arames esticados no sentido horizontal.

A colheita foi realizada em 29-052007, data em que a região de abscisão dos frutos apresentou rachadura em todo o seu perímetro, sendo colhidos todos os frutos de cada tratamento de uma só vez. As características avaliadas foram: sólidos solúveis (SS), obtidos através de refratômetro manual; $\mathrm{pH}$, determinado em peagâmetro digital; ácido ascórbico (Vit. C), 
expresso em mg de ácido ascórbico por 100 mL de suco; acidez titulável (AT), expresso em \% de ácido cítrico; índice de maturação (RATIO), obtido pela relação entre SS/AT; rendilhamento da casca, adotando-se escala de notas conforme metodologia de Rizzo (2001); diâmetro e comprimento dos frutos (mm) e lóculos (mm),obtidos através de medição com régua graduada; espessura da polpa $(\mathrm{mm})$, obtido através de paquímetro digital; massa fresca dos frutos, obtida através de pesagem em balança analítica e produção por planta. Com os dados médios de cada característica, realizou-se a análise de variância, sendo as médias comparadas pelo teste de Tukey $(\mathrm{p}<0,05)$.

\section{RESULTADOS E DISCUSSÃO}

Não houve interação significativa entre os fatores híbridos de melão e o número de frutos por planta para nenhuma das características avaliadas. Portanto, os fatores são apresentados e discutidos separadamente.

As maiores médias para o teor de sólidos solúveis foram obtidas para os tratamentos em que as plantas foram conduzidas com dois e três frutos, diferindo do tratamento com quatro frutos (Tabela 1). O mesmo resultado foi obtido por Seabra Junior et al. (2003) e Castoldi et al. (2008), os quais comprovaram que plantas mantidas com maior número de frutos resultaram em frutos com menor teor de açúcares, embora maior produtividade.

Esta diferença se deve ao fato de que os frutos provenientes de plantas com apenas dois e três frutos tiveram maior disponibilidade e aporte de fotoassimilados para o fruto, em razão da maior área foliar por fruto. Segundo Welles \& Buitelaar (1988), a maior proporção de área foliar pode contribuir para a obtenção de frutos com alto teor de sólidos solúveis.

Tabela 1. Médias de sólidos solúveis (SS), pH, ácido ascórbico (AA), acidez titulável (AT), índice de maturação (RATIO) e rendilhamento da casca (RC) de dois híbridos de melão rendilhado avaliados em função do número de frutos por planta. Jaboticabal, UNESP- FCAV, 2007.

\begin{tabular}{|c|c|c|c|c|c|c|}
\hline Tratamentos & $\begin{array}{c}\mathrm{SS} \\
\left({ }^{\circ} \text { Brix }\right)\end{array}$ & $\mathrm{pH}$ & AA & $\begin{array}{c}\text { AT } \\
\% \text { ác. } \\
\text { cítrico }\end{array}$ & $\begin{array}{c}\text { RATIO } \\
\text { (SST/AT) }\end{array}$ & $\mathrm{RC}$ \\
\hline \multicolumn{7}{|l|}{$\mathrm{N}^{\circ}$ frutos } \\
\hline 2 & $12,50 \mathrm{a}$ & 6,62 & 99,87 & 0,07 & $183,19 \mathrm{a}$ & $2,81 \mathrm{a}$ \\
\hline 3 & $10,73 a$ & 6,66 & 113,23 & 0,06 & $167,64 \mathrm{a}$ & $2,84 a$ \\
\hline 4 & $8,73 b$ & 6,29 & 132,08 & 0,08 & $114,89 \mathrm{~b}$ & $2,22 b$ \\
\hline Teste F & $42,940 * *$ & $3,987^{\mathrm{NS}}$ & $2,394^{\mathrm{NS}}$ & $1,79^{\mathrm{NS}}$ & $13,25 * *$ & $9,65^{*}$ \\
\hline \multicolumn{7}{|l|}{ Cultivares } \\
\hline Louis & 10,16 & $6,37 \mathrm{~b}$ & 106,84 & 0,08 & $135,52 b$ & 2,52 \\
\hline Bônus $n^{\circ} 2$ & 11,15 & $6,67 \mathrm{a}$ & 123,27 & 0,07 & $174,96 \mathrm{a}$ & 2,74 \\
\hline Teste F & $8,908^{\mathrm{NS}}$ & $6,885 *$ & $1,851^{\mathrm{NS}}$ & $4,043^{\mathrm{NS}}$ & $12,062 * *$ & $2,88^{\mathrm{NS}}$ \\
\hline \multicolumn{7}{|l|}{ Interação } \\
\hline Teste F & $0,349^{\mathrm{NS}}$ & $2,067^{\mathrm{NS}}$ & $1,606^{\mathrm{NS}}$ & $1,459^{\mathrm{NS}}$ & $1,437^{\mathrm{NS}}$ & $0,97^{\mathrm{NS}}$ \\
\hline $\mathrm{CV}(\%)$ & 7,64 & 4,33 & 25,72 & 18,52 & 17,92 & 12,14 \\
\hline
\end{tabular}

(2) Médias seguidas da mesma letra na coluna não diferem entre si pelo teste de Tukey (p>0,05).

**, * e NS, significativo $(\mathrm{p}<0,01)$, significativo $(\mathrm{p}<0,05)$ e não significativo $(\mathrm{p}>0,05)$ pelo teste $\mathrm{F}$, respectivamente. 
Considerando-se o valor mínimo de sólidos solúveis aceitável para a comercialização ( $9^{\circ}$ Brix) (SANDRI et al., 2007), e com base nas observações desse trabalho, somente os frutos provenientes de plantas com dois e três frutos se enquadrariam como melão tipo exportação.

O pH observado para o híbrido Bônus $\mathrm{n}^{\mathrm{o}} 2$ foi superior aquele do Louis, no entanto, o número de frutos por planta não afetou significativamente esta característica em função do híbrido. Os valores de $\mathrm{pH}$ obtidos neste trabalho foram semelhantes aos de Castoldi et al. (2008) e Rizzo \& Braz (2001), ao compararem cultivares de melão rendilhado em casa de vegetação. Os valores de $\mathrm{pH}$ variaram entre 6,37 e 6,67, estando próximo dos valores limites aceitáveis para comercialização (CARVALHO \& CASTRO, 2002).

Quanto ao ácido ascórbico e acidez titulável não houve diferença significativa para ambos os fatores avaliados, com valores médios de acidez titulável semelhantes às obtidas por Queiroga et al. (2009) e Melo et al. (2011), os quais encontraram valores entre 0,06 e 0,09\%. Castoldi et al. (2008), avaliando o número de frutos por planta, também não obtiveram diferença significativa para estas características, porém obtiveram valores inferiores de acidez total titulável para o híbrido Bônus $\mathrm{n}^{\circ} 2$, diferente dos resultados obtidos neste experimento, que não apresentou diferença para os materiais genéticos.

Para o índice de maturação, as plantas com dois e três frutos obtiveram as maiores médias do que o tratamento com quatro frutos. Isto pode ter ocorrido pelo fato da colheita ter sido realizada de uma única vez, o que fez com que alguns frutos, principalmente aqueles provenientes de plantas conduzidas com quatro frutos, apresentassem estádio de maturação incompleto. Já entre os híbridos, Bônus $\mathrm{n}^{\circ} 2$ obteve média superior a Louis, em razão daquele ser um híbrido mais precoce, atingindo o ponto de colheita antes de Louis.

O maior índice de maturação para plantas com menor número de frutos se deve ao maior teor de sólidos solúveis, que elevou a relação $\mathrm{SS} / \mathrm{AT}$ e proporcionou incremento de açúcares no fruto em relação a ácidos.

Segundo Godoy \& Cardoso (2003), o ácido cítrico, principal componente das frações de ácidos orgânicos no meloeiro, pode ser usado no processo respiratório ou na conversão de açúcares. Este ácido é utilizado principalmente no período de maturação dos frutos, causando modificações no sabor do melão devido a alterações nos compostos aromáticos, ácidos orgânicos e açúcares solúveis (VILLANUEVA et al.,2004).

$\mathrm{O}$ rendilhamento da casca, apesar de não ter sido influenciado pelo fator genótipo (híbrido), foi influenciado pelo fator número de frutos por planta, sendo as plantas cultivadas com dois e três frutos as que obtiveram rendilhamento mais intenso, com médias de 2,81 e 2,84, respectivamente. Isto se deve a taxa mais lenta de maturação quando maior número de frutos é mantido por planta. Não houve interação entre os fatores número de frutos por planta e híbridos para nenhuma das características avaliadas (Tabela 2), portanto estas serão discutidas separadamente.

Não houve diferença significativa entre os híbridos, para todas as características produtivas avaliadas. Isto demonstra a semelhança produtiva entre os dois materiais genéticos, sendo os híbridos do grupo Cantalupensis os mais cultivados no estado de São Paulo. A quantidade de frutos por planta afetou de forma significativa as características físicas dos frutos, sendo que nas plantas mantidas com apenas dois frutos obtiveram-se maiores médias de diâmetro e comprimento dos frutos, comprimento do lóculo e massa fresca dos frutos, diferindo 
Tabela 2. Médias do diâmetro dos frutos (DF), comprimento dos frutos (CF), diâmetro dos lóculos (DL), comprimento dos lóculos (CL), espessura das polpas (EP), massa fresca dos frutos (MFF) e produção por planta (PP) de dois híbridos de melão rendilhado conduzidos com diferentes números de frutos por planta. Jaboticabal, UNESPFCAV, 2007.

\begin{tabular}{lccccccc}
\hline \hline Tratamentos & $\begin{array}{c}\mathrm{DF} \\
(\mathrm{mm})\end{array}$ & $\begin{array}{c}\mathrm{CF} \\
(\mathrm{mm})\end{array}$ & $\begin{array}{c}\mathrm{DL} \\
(\mathrm{mm})\end{array}$ & $\begin{array}{c}\mathrm{CL} \\
(\mathrm{mm})\end{array}$ & $\begin{array}{c}\mathrm{EP} \\
(\mathrm{mm})\end{array}$ & $\begin{array}{c}\text { MFF } \\
(\mathrm{kg})\end{array}$ & $\begin{array}{c}\text { PP } \\
\left(\mathrm{kg} \mathrm{pl}^{-1}\right)\end{array}$ \\
\hline $\mathbf{N}^{\mathbf{0}}$ frutos & & & & & & & \\
\hline 2 & $135,72 \mathrm{a}$ & $143,59 \mathrm{a}$ & $53,51 \mathrm{a}$ & $82,88 \mathrm{a}$ & $43,54 \mathrm{a}$ & $1,28 \mathrm{a}$ & $2,55 \mathrm{c}$ \\
3 & $125,29 \mathrm{~b}$ & $129,28 \mathrm{~b}$ & $49,77 \mathrm{a}$ & $73,11 \mathrm{~b}$ & $40,12 \mathrm{a}$ & $1,01 \mathrm{~b}$ & $3,01 \mathrm{~b}$ \\
4 & $112,01 \mathrm{c}$ & $114,94 \mathrm{c}$ & $45,45 \mathrm{~b}$ & $66,13 \mathrm{c}$ & $34,17 \mathrm{~b}$ & $0,82 \mathrm{c}$ & $3,26 \mathrm{a}$ \\
\hline Teste F & $37,21^{* *}$ & $38,69^{* *}$ & $12,05^{* *}$ & $35,28^{* *}$ & $23,65^{* *}$ & $21,85^{* *}$ & $8,77^{* *}$ \\
\hline Cultivares & & & & & & \\
\hline Louis & 122,69 & 27,25 & 48,79 & 73,79 & 38,72 & 1,07 & 2,85 \\
Bônus $\mathrm{n}^{\mathbf{o}} 2$ & 125,99 & 31,29 & 50,35 & 74,29 & 39,84 & 0,99 & 3,03 \\
\hline Teste F & $2,16^{\mathrm{NS}}$ & $2,32^{\mathrm{NS}}$ & $1,34^{\mathrm{NS}}$ & $0,09^{\mathrm{NS}}$ & $0,99^{\mathrm{NS}}$ & $2,28^{\mathrm{NS}}$ & $1,70^{\mathrm{NS}}$ \\
\hline Interação & & & & & & \\
\hline Teste F & $2,15^{\mathrm{NS}}$ & $1,80^{\mathrm{NS}}$ & $1,99^{\mathrm{NS}}$ & $1,86^{\mathrm{NS}}$ & $1,18^{\mathrm{NS}}$ & $1,56^{\mathrm{NS}}$ & $2,02^{\mathrm{NS}}$ \\
\hline CV $(\%)$ & 4,43 & 5,04 & 6,63 & 5,41 & 7,02 & 13,66 & 11,58 \\
\hline \hline
\end{tabular}

(2) Médias seguidas da mesma letra na coluna não diferem entre si pelo teste de Tukey (p>0,05).

**, * e NS, significativo $(p<0,01)$, significativo $(p<0,05)$ e não significativo $(p>0,05)$ pelo teste $F$, respectivamente.

significativamente das plantas mantidas com três e quatro frutos. O mesmo foi observado por Kano et al. (2010), os quais obtiveram valores de diâmetro e comprimento dos frutos de 106,39 $\mathrm{mm}$ e $122,72 \mathrm{~mm}$, respectivamente. Isto se deve, provavelmente, à manutenção de menor número de frutos por plantas, crescendo simultaneamente na planta.

Maruyama et al. (2000) observaram que, quando os frutos são fixados na planta ainda jovem, entre o $5^{\circ}$ e $8^{\circ}$ nós, ocorre a má formação dos frutos, provavelmente devido a relação fonte:dreno ainda ser muito pequena, o que levou à menor produção total por planta. Em pepino, Marcelis (1996) observou que o aumento na taxa de crescimento de frutos ocorreu em detrimento do crescimento da parte vegetativa e viceversa. Para Marcelis (1996), a força do dreno (habilidade competitiva para importar fotoassimilados), correlaciona-se não somente com o número de drenos, mas também com a massa individual dos drenos.
Com relação ao diâmetro do lóculo e espessura da polpa, frutos oriundos de plantas com apenas dois frutos apresentaram os maiores valores, diferindo significativamente apenas dos frutos provenientes de plantas conduzidas com quatro frutos. Segundo Fernandez (2001), a espessura da polpa deve ser a maior possível, tendo assim maior aceitação pelo mercado consumidor, tanto interno como externo.

De maneira geral, os frutos de plantas conduzidas com dois ou três frutos apresentam maiores dimensões que os provenientes de plantas com quatro frutos. Isto se deve provavelmente ao fato de que a competição por fotoassimilados em plantas com dois ou três frutos é menor do que em plantas com quatro frutos, proporcionando assim melhor desenvolvimento e consequentemente maiores dimensões. Purquerio et al. (2003), ao avaliar a concentração de nitrogênio na solução nutritiva e número de frutos por planta, verificaram maior produção nos tratamentos 
com maior número de frutos por planta, demonstrando tendência de queda na produtividade com a diminuição do número de frutos colhidos por planta.

Estes resultados foram confirmados por Duarte \& Peil (2010), os quais sugeriram que, para o meloeiro, a saturação da carga de frutos se dá a partir de dois frutos por planta, pois a partir desse momento, a demanda de fotoassimilados pelos frutos eleva-se bruscamente. Entretanto, o aparecimento de mais um novo fruto compete mais com os frutos remanescentes do que com os órgãos vegetativos.

Para a característica produção por planta, a maior produção foi encontrada no tratamento com quatro frutos $\left(3,26 \mathrm{~kg} \cdot \mathrm{ha}^{-1}\right)$. Observa-se que maiores produções podem ser obtidas com o aumento no número de frutos mantidos por planta, já que maior número de frutos pode ser obtido numa mesma área, refletindo em maior produtividade.

\section{CONCLUSÕES}

A cultivar Bônus $n^{\circ} 2$ produz frutos de melhor qualidade ("ratio") e a condução com três frutos por planta crescendo simultaneamente compatibiliza a produtividade com a qualidade do fruto.

\section{REFERÊNCIAS BIBLIOGRÁFICAS}

CARVAlHO, E.P.; CASTRO, H.A. 2002. Controle microbiológico e fitossanitário de alimentos. Curso de Pós-graduação "Lato Sensu" (Especialização) à distância: Tecnologia e qualidade de alimentos vegetais. Lavras, UFLA/FAEPE, $122 \mathrm{p}$.

CASTEllane, P. D.; ARAÚJO; J. A. C. 1994. Cultivo sem solo: hidroponia. Jaboticabal: FUNEP, 43p.

CASTOLDI, R.; CHARLO, H.C.O.; VARGAS, P.F.; BRAZ, L.T. 2008. Qualidade de frutos de cinco híbridos de melão rendilhado em função do número de frutos por planta. Revista Brasileira de Fruticultura, Jaboticabal, v.30, n.2, p. $455-458$

COELHO, E. L.; FONTES, P.C.R.; FINGER, F.L.; CARDOSO, A.A. 2003. Qualidade de fruto de melão rendilhado em função de doses de nitrogênio. Bragantia, Campinas, v. 62, n. 2, p. 173-178

DUARTE, T.S.; PEIL, R.M.N.; BACCHIS, S.; STRASSBURGUER, A.S. 2008. Efeito da carga de frutos e concentrações salinas no crescimento do meloeiro cultivado em substrato. Horticultura Brasileira, Vitória da Conquista, v. 26, p. 348-353

DUARTE, T.S.; PEIL, R.M.N. 2010. Relações fonte:dreno e crescimento vegetativo do meloeiro. Horticultura Brasileira, Vitória da Conquista, v. 28, p. 271-276

FERNANDEZ, A. L. T. 2001. Fertirrigação na cultura do melão em ambiente protegido, utilizando fertilizantes organominerais e químicos. 108p. Tese (Doutorado em Engenharia Agrícola) - Faculdade de Engenharia Agrícola, Universidade de Campinas, Campinas.

GODOY, A. R.; CARDOSO, A. I. I. 2003. Curva de crescimento e qualidade de frutos de melão rendilhado sob cultivo protegido. Revista Ceres, Viçosa, v. 50, n. 289, p. 220-303

KANO, C.; CARMELLO, Q.A.C.; CARDOSO, S.S.; FRIZZONE, J.A. 2010. Acúmulo de nutrientes pelo meloeiro rendilhado cultivado em ambiente protegido. Semina: Ciências Agrárias, Londrina, v.31, p.1155-1164

MARCELIS, L.F.M. 1996. Sink strength as a determinant of dry matter partitioning in the whole plant. Journal of Experimental Botany, v.47, p.12811291 
MARCELIS, L.M.F. 1992. The dynamics of growth and dry matter distribution in cucumber. Annals of Botany, 69: 487492.

MARTINS, S. R.; PEIL, R. M.; SCHWENGBER, J. E.; ASSIS, F. N.; MENDEZ, M. E. G. 1998. Produção de melão em função de diferentes sistemas de condução de plantas em ambiente protegido. Horticultura Brasileira, Vitória da Conquista, v. 16, n. 1, p. 2430

MARUYAMA, W.I.; BRAZ, L.T.; CECÍllO FILHO, A.B.. 2000. Condução de melão rendilhado sob cultivo protegido. Horticultura Brasileira, Vitória da Conquista, 18: 175-179.

MELO, D.M.; CHARLO, H.C.O.; CASTOLDI, R.; BRAZ, L.T. 2011. Acúmulo de macronutrientes no meloeiro rendilhado cultivado em substrato. Horticultura Brasileira, Vitória da Conquista, 29: 3735-3743.

QUEIROGA, R.C.F.; PUIATTI, M.; FONTES, P.C.R.; CECON, P.R. 2009. Características de frutos do meloeiro variando número e posição de frutos na planta. Horticultura Brasileira, Vitória da Conquista, v. 27, p. 23-29

PÁDUA, J. G. 2001. Cultivo protegido de melão rendilhado, em duas épocas de cultivo. 108p. Tese (Doutorado em Agronomia-Produção Vegetal) Faculdade de Ciências Agrárias e Veterinárias de Jaboticabal, Universidade Estadual Paulista, Jaboticabal.

PEIL, R.M.N.; GALVÉZ, J.L.. 2005. Reparto de materia seca como factor determinante de la producción de las hortalizas de fruto cultivadas em invernadero. Revista Brasileira Agrociência, Pelotas, 11: 05-11

PURQUERIO, L. F. V.; CECILIO FILHO, A.B.; BARBOSA, J.C. 2003. Efeito da concentração de nitrogênio na solução nutritiva e do número de frutos por planta sobre a produção do meloeiro. Horticultura Brasileira, Vitória da Conquista, v. 21, n. 2, p. 186-191

RIZZO, A. A. N.; BRAZ, L. T. 2001. Características de cultivares de melão rendilhado cultivadas em casa de vegetação. Horticultura Brasileira, Vitória da Conquista, v. 19, n. 3, p. 370373

SANDRI, D.; RINALDI, M.M.; SOUZA, M.R.; OLIVEIRA, H.F.E.; TELES, L.M. 2007. Desenvolvimento e qualidade do melão cultivado no sistema hidropônico sob diferentes substratos e formato do leito de cultivo. Irriga, Botucatu, v.12, n.2, p.156-167

SEABRA JÚNIOR, S.; PANTANO, S.C.; HIDALGO, A.F.; RANGEL, M.G.; CARDOSO, A.I.I. 2003. Avaliação do número e posição do fruto de melancia produzido em ambiente protegido. Horticultura Brasileira, Vitória da Conquista, v.21, p. 708-711

VALANTIN, M.; GARY, C.; VAISSIÈRI, B.E.; FROSSARD, J.S. 1999. Effect of load on partitioning of dry matter and energy in Cantaloupe (Cucumis melo L.). Annals of Botany, v.84, p. 173-181

VILLANUEVA, M.J.; TENORIO, M. D.; ESTEBAN, M. A.; MENDOZA, M. C. 2004. Compositional changes during ripening of two cultivars of muskmelon fruits. Food Chemistry, v. 87, p. 179185

WELLES, G.W.H.; BUITELAAR, K. 1988. Factors affecting soluble solids content of muskmelon. Netherlands Journal of Agricultural, Wageningen, v. 36 p. 239-246

Recebido em: 13/3/2013 Aceito para publicação em: 7/2/2014 